\title{
O modelo de atenção à saúde e o uso de ansiolíticos entre mulheres ${ }^{1}$
}

\author{
Lúcia de Fátima Carvalho \\ Magda Dimenstein \\ Universidade Federal do Rio Grande do Norte
}

\begin{abstract}
Resumo
Este trabalho objetiva discutir dependência química de ansiolíticos em mulheres, tomando como eixo de análise a relação que se estabelece entre a mulher, o medicamento e o serviço de saúde. A população estudada foi composta de dezessete mulheres usuárias de ansiolíticos que utilizam o serviço público de Natal, Rio Grande do Norte. O instrumento utilizado foi a entrevista semi-estruturada, com a técnica de análise das práticas discursivas. Consideramos que o tipo de atendimento prestado à mulher, ou seja, a produção de serviços de saúde voltados para essa clientela e sua utilização, contribuem, sobremaneira, para o uso indiscriminado desses medicamentos e conseqüentemente para o fenômeno da dependência. Observamos também que a relação entre esses elementos reforça a medicalização da mulher e repercute sobre o seu processo de saúde/doença.

Palavras-chave: medicamentos ansiolíticos; mulheres; serviço público de saúde
\end{abstract}

\begin{abstract}
The health attention model and the use of anxiolytic by women. This work discusses the chemical dependence of anxiolytic drugs by women, analyzing the relation between women, drug, and public health service. The participants were seventeen women, all of them anxiolytic users, attending public health service at the city of Natal, Rio Grande do Norte, Brazil. A semi-structured interview was used as research instrument, associated with methodological analysis of user's speeches. We consider that health service, usually available and produced for this kind of patient, with generalized prescription and utilization of anxiolytics, is taking women to dependence on these drugs. We observed also that the relation between these elements reinforces woman's medicalization, and affects their health/disease process.
\end{abstract}

Key words: anxiolytic drugs; women; public health service

O saber que se dirige ao êxito técnico constrói objetos, enquanto o saber na direção do sucesso existencial é o que constitui sujeitos (Gadamer, 1996, citado por Ayres, 2001, p. $67)$.

$\mathrm{E}$ sse trabalho objetiva discutir dependência química de ansiolíticos em mulheres que utilizam o serviço público de saúde de Natal tomando como eixo de análise a relação que se estabelece entre a mulher, o medicamento e o serviço de saúde, no que se refere ao modelo assistencial hegemônico. Nosso interesse é apontar que o tipo de atendimento prestado à mulher, ou seja, a produção de serviços de saúde voltados para essa clientela e sua utilização, contribui, sobremaneira, para o uso indiscriminado desses medicamentos e conseqüentemente para o fenômeno da dependência. Além disso, consideramos que na relação mulher-serviço de saúde é produzido um tipo de discurso naturalizado que subjuga a mulher, na medida em que não leva em conta os modos de existência particulares, as singularidades e a diversidade das maneiras de sentir e pensar de cada sujeito. Assim, no contexto da atenção à saúde, observamos práticas e saberes que buscam a modelagem, a serialização e homogeneização das subjetividades, isto é, são produzidas ações que se afastam da perspectiva do cuidado - elemento imprescindível da atividade assistencial - trazida por Ayres (2001), para quem a atitude de cuidar não pode ser apenas uma pequena e subordinada tarefa parcelar das práticas de saúde.

Cuidar da saúde de alguém é mais que construir um objeto e intervir sobre ele. Para cuidar há que se considerar e construir projetos; há que se sustentar, ao longo do tempo, uma relação entre a matéria e o espírito, o corpo e a mente, moldados a partir de uma forma que o sujeito quer opor à dissolução, inerte e amorfa, de sua presença no mundo (p. 71).

Nesse sentido, podemos considerar que o modelo de atenção à saúde, hegemônico, não abre espaço para a exploração de novas possibilidades existenciais para as mulheres na medida em que está centrado no sintoma, na doença e na crença da neutralidade das técnicas e intervenções, o qual 
funciona como dispositivo de normatização social, de disciplinarização das atitudes e docilização das forças de ruptura (Melman, 2001).

Para discutir essas questões vamos trabalhar a partir do discurso de mulheres entrevistadas no serviço público de saúde de Natal, buscando articular sua fala, o simbolismo do medicamento e o modelo de atenção à saúde.

\section{Da relação entre produção de serviços de saúde e dependência química}

O consumo de ansiolíticos tornou-se um problema complexo de saúde pública que atinge grandes dimensões. A literatura nacional e internacional é unânime em afirmar a posição de destaque das mulheres em relação ao consumo desses medicamentos, os quais estão entre as substâncias psicotrópicas mais consumidas de forma indiscriminada em todo o mundo. O consumo deles pode acarretar alterações no comportamento, como também levar à dependência psíquica e/ou física $^{2}$, resultando muitas vezes em complicações pessoais e sociais graves. Tais medicamentos ansiolíticos são os chamados calmantes, tranqüilizantes e sedativos, que agem sobre o sistema nervoso central, exercendo uma ação seletiva sobre a ansiedade. O uso dessas substâncias, na atualidade, ocorre geralmente de forma indiscriminada, sendo indicados e amplamente usados no combate à insônia.

Numa visão abrangente, Barros (1983), desde o início da década passada, vem afirmando que esses medicamentos “fazem parte do arsenal terapêutico dirigido à 'medicalização do mal-estar’ e ao controle da tensão gerada, não raras vezes, nas relações sociais de produção e no processo de trabalho" (p. 94). Em outras palavras, as pessoas recorrem a calmantes, na esperança de escapar das pressões sociais, familiares ou do trabalho ou torná-las, ao menos, toleráveis.

Os benzodiazepínicos (BZD) ${ }^{3}$ foram introduzidos no mercado no início da década de sessenta, coincidindo com o aumento das drogas psicoativas, de acordo com Soares, Soares, Asbahr e Bernik (1991). Essas substâncias substituíram, nessa década, praticamente todas as drogas utilizadas no tratamento da ansiedade - barbitúricos, meprobamato, hidrato de cloral e outros - que provocavam sérios efeitos colaterais. Vieram a substituir com amplas vantagens esses agentes predecessores, na medida em que eram menos tóxicos e tinham menor potencialidade de provocar acidentes fatais e menor tendência para produzir tolerância farmacológica ${ }^{4}$ (Karniol et al., 1986). Foi exatamente essa segurança que criou certa irresponsabilidade generalizada no uso dos BDZ, tanto da parte dos médicos, como dos pacientes e dos laboratórios, a partir da década de setenta.

Há uma concordância geral de que os BDZ devem ser usados no tratamento da ansiedade em curto prazo, não devendo exceder de dois a quatro meses, exceto em casos muito especiais. No entanto, o que se vê na prática, é a continuidade de um uso que vai além de uma finalidade específica e com um tempo indeterminado, em que o medicamento passa a ocupar um lugar fundamental e imprescindível na vida de muitos indivíduos.
O fenômeno da medicalização, apesar de não ser um problema atual, como sugere a literatura do campo apresentada nesse trabalho, está muito presente nos dias de hoje e ocupa um lugar importante no jogo de interesses do poder econômico. O consumo de medicamentos tem um significativo impacto na sociedade, haja vista constituir o principal meio de combate à doença na prática terapêutica atual e também por ter relevante significância em termos econômicos. Aliado a isso, existe o fato das consultas médicas resultarem quase sempre numa prescrição, decorrente de uma visão limitada da saúde, para a qual o medicamento tornou-se a principal ferramenta.

Acerca desse fenômeno, Barros (1995) expõe uma definição de medicalização que não se restringe ao consumo de medicamentos, mas também “à elevada dependência em relação à oferta de serviços ou bens de natureza médicoassistencial e seu consumo intensivo” (p. 25). D e s s a maneira, junto ao consumo desses bens de saúde há uma crença de que, se existe um problema, ele deve ser abolido da forma mais rápida e o medicamento ocupa o lugar da concretização dessa possibilidade, passando a estar vinculado ao bem-estar, à saúde ou mesmo à felicidade.

Esse fenômeno da medicalização, na concepção desse autor, é de que foi reforçado duplamente: pelo raciocínio mecanicista e pela lógica capitalista de mercado. Como conseqüência disso, todos os bens e serviços de saúde passaram a ser considerados mercadorias que devem gerar lucro. O que resultou do incremento da medicalização foi a intensificação da dependência. A sua visão a esse respeito é a seguinte:

As pessoas pretendem, cada vez com maior freqüência, resolver seus problemas - sejam ou não susceptíveis de serem classificados como "problemas médicos" - recorrendo aos serviços oferecidos pelo sistema de saúde. Isto não somente levou a uma hipervalorização do papel da Medicina e de seu instrumental tecnológico, mas provocou, igualmente, progressivo aumento da perda da capacidade das pessoas na conquista de alternativas para a resolução de problemas amiúde vinculados a fatores de ordem extramédica. (p. 32)

Por conseguinte, deixa-se de ter uma visão ampla dos problemas e de seus determinantes, resultando numa crença generalizada de que não parece ser possível enfrentar a doença sem a presença do arsenal terapêutico oferecido pelo sistema médico-industrial.

Assim, o medicamento aparece como uma mercadoria, cujo consumo deve ser estimulado ao máximo, pois o que interessa aos setores de produção e comercialização de medicamentos é a ocorrência de um máximo de doenças, acompanhadas de um máximo de tratamento, em outras palavras, de medicalização. O medicamento aparece, pois, como uma mercadoria especial, respaldada pelo conhecimento científico, o qual é tomado como verdade absoluta. À medida que o medicamento assume essa conotação de mercadoria, assume também, de acordo com Barros (1983), um duplo papel ao satisfazer, ao mesmo tempo, os interesses do capital e do modelo de saúde hegemônico da categoria médica. 
A visão de Rozemberg (1994) nesse sentido é de que “a medicalização de 'nervos', resultante de sua redução a um conjunto de sintomas, concorre para a perpetuação do 'nervoso’ como doente crônico e para a manutenção do fenômeno no nível de um problema individual” (p. 306). Esse mesmo autor nos lembra ainda que a educação dos médicos é concluída pelas indústrias farmacêuticas, que têm presença cada vez mais marcante nos cursos de formação médica.

Além da concepção de mercadoria, o medicamento também pode ser visto como símbolo de saúde, de acordo com Lefèvre (1983). Isso se dá em função de o organismo humano ser visto como sede da saúde. Essa noção de saúde, na ótica desse autor, é de um estado orgânico, e o medicamento contém em si esse estado orgânico. A sua visão é de que: "os medicamentos são imitações da vida enquanto fato orgânico, pedaços de vida orgânica (sono, tranqüilidade, potência sexual, etc.) comprimidos num comprimido, ou numa gota, ou num xarope” (p. 60). Essas mercadorias incorporam em si a saúde, passando a representá-la, a simbolizá-la.

No que se refere ao modelo de atenção oferecido no Brasil, especificamente no serviço público de saúde, percebemos que o mesmo se mostra cada vez mais ineficaz, resultando na perpetuação de situações que estão longe de proporcionar uma melhor saúde para quem necessita dos seus benefícios. O modelo biomédico hegemônico alimenta o sistema vigente na medida em que reforça a dicotomia saúde/ doença, o que implica uma restrita atuação voltada exclusivamente para a doença. Ele vem fundamentar práticas, na maioria das vezes, inadequadas para tratar as necessidades de saúde da população. O mesmo é basicamente condicionado pelo paradigma cartesiano, que criou uma imagem inflexível dos organismos vivos como sistemas. É baseado numa estrutura conceitual que considera o corpo como uma máquina, a qual pode ser completamente entendida em termos da organização e do funcionamento de suas peças. Como conseqüência, temos uma abordagem técnica de saúde, na qual a doença é reduzida a uma avaria mecânica, e a terapia médica, à manipulação técnica, negligenciando os aspectos psicológicos, sociais e ambientais do processo saúde/doença.

Nesse modelo de prática médica, é atribuído muito poder aos profissionais, os quais são colocados numa posição em que somente eles sabem o que é importante para a saúde dos indivíduos e só eles podem fazer qualquer coisa a esse respeito. "Nossa sociedade conferiu aos mesmos o direito exclusivo de determinar o que constitui a doença, quem está doente e quem não está, e os procedimentos com relação ao indivíduo enfermo” (Capra, 1982, p. 151).

O modelo prioritário de assistência em questão é do tipo pronto-atendimento da demanda espontânea, apoiado nessa concepção "biologizante” que por ser, na maioria das vezes, ineficaz, possibilita o constante retorno aos centros de saúde. Isso faz aumentar a demanda, a produtividade e, conseqüentemente, os gastos. Revela-se, portanto, além de ineficaz, dispendioso.

Esse modelo de assistência à saúde, ao qual estamos submetidos, está relacionado com a forma neoliberal de pro- dução dos serviços de saúde no nosso país. O seu funcionamento na visão de Campos (1992) reproduz a forma mecanicista da prática, a qual sobrevive articulando interesses empresariais com os de amplas parcelas de profissionais de saúde, principalmente as dos médicos e dentistas. A prática de atendimentos na saúde pública, assentada nos moldes das concepções desse modelo neoliberal, é voltada para assistência individual. Temos como resultado disso o incentivo ao aspecto quantitativo: a produtividade traduzida em números de procedimentos realizados ${ }^{5}$. Ou seja, ao longo dos últimos anos, nota-se um acirramento dessas práticas de saúde e a hegemonia do modelo assistencial curativo, a despeito das inúmeras experiências desenvolvidas no país voltadas para a construção de inovações tanto no processo de formação profissional, quanto nas práticas, gerência dos serviços de saúde e cultura institucional (Almeida, Feuerwerker, \& Llanos, 1999).

Os centros e postos de saúde geralmente adotam a modalidade de pronto atendimento e são direcionados à demanda espontânea da comunidade. Desenvolvem ações padronizadas de atendimento, tais como: vacinação, puericultura, pré-natal, etc. Apesar do crescimento do número de unidades de atenção básica, ainda não se conseguiu concretizar um atendimento mais integral à saúde da população, através de ações voltadas ao mesmo tempo para o indivíduo e para a comunidade, para a promoção, prevenção e tratamento ${ }^{6}$ na perspectiva de superar os limites da prática clínica. No entanto, o que persiste é uma atenção predominantemente curativa, com ações de atendimentos individuais.

A equipe que trabalha nas Unidades Básicas de Saúde (UBS) teve uma ampliação em termos qualitativos a partir da contratação de novos profissionais, como psicólogos, assistentes sociais, entre outros, renovou um pouco as práticas de atendimento, tornando-as mais ampliadas, no sentido de contemplarem mais a complexidade humana, através de atendimentos psicológicos, trabalhos em grupo, educação em saúde, reabilitação ${ }^{7}$ e outros. Apesar de esse fato ter possibilitado uma superação dos limites de atenção individual curativa, essas atividades não foram suficientes para a ocorrência de mudanças efetivas, como esclarece Campos (1992): "Não conseguiram, enquanto atores políticos, criar uma dinâmica política capaz de superar a privatização e a burocratização do SUS, prevalecendo, mesmo entre esses funcionários, uma situação de progressiva adaptação a pasmaceira do sistema público” (p. 124).

O psicólogo, como parte dessa equipe, está submetido a esse modelo de trabalho. Os que estão atuando no serviço público de saúde apresentam dificuldades de oferecer alternativas de atuação mais ampliadas, restringindo-se àquelas aprendidas durante a sua formação acadêmica, que são baseadas, predominantemente, em um modelo clínico e individual. Sua formação profissional não o preparou para atender na saúde pública, pois o ensino dentro da psicologia sempre priorizou o modelo clínico psicoterápico. Trata-se de um tipo de prática que historicamente sempre foi voltada para os padrões de classe média e que, atualmente, é utilizada de 
forma padronizada no atendimento à população mais carente. Consideramos, porém, que a atuação do psicólogo é descontextualizada nas instituições de saúde pública, pois além de desconsiderar aspectos importantes relacionados com a condição socioeconômica e cultural das camadas populares, impede a integração de ações relacionadas à saúde. Deseja-se que essa categoria tenha, entre outras coisas, uma função social e que a sua prática seja condizente com a realidade da população assistida, desenvolvendo uma postura crítica em relação aos pressupostos teóricos.

A partir da análise desenvolvida a respeito do modelo de assistência à saúde, podemos observar que a população não está sendo atendida de modo a contemplar as suas reais necessidades. Tendo em vista que a mulher aparece como grande consumidora dos serviços e bens de saúde, nota-se que ela está à mercê de um atendimento que se mostra longe de ser adequado para a resolução dos seus problemas de saúde.

Autores como Fonseca (1999) e Oliveira (2000) mostram que os serviços de saúde geralmente se organizam para atender a mulher no seu ciclo gravídico-puerperal, como no acompanhamento pré-natal, assistência ao parto e puerpério, mesmo assim de forma deficiente. Fonseca (1999) afirma que alguns aspectos de assistência têm sido relegados a plano secundário, tais como: prevenção, detecção e terapêutica de doenças de transmissão sexual, repercussões biopsicossociais da gravidez não desejada, abortamento e acesso a métodos e técnicas de controle da fertilidade. Verificamos, então, que o sistema de saúde, da forma como funciona, não atende às especificidades da mulher, na medida em que está voltado somente para os aspectos físicos e biológicos.

A despeito disso, a forma de assistência oferecida nos serviços de saúde mostra-se tecnificada, padronizada, medicalizada e, na maioria das vezes, não se transforma em benefícios reais para as mulheres usuárias. Existe uma tendência geral por parte dos profissionais em relacionar a saúde da mulher à mera questão reprodutiva, esquecendo que ela é, além de mãe, uma cidadã com direitos e necessidades variadas.

Sem dúvida, nas últimas décadas, a mulher vem assumindo muitos papéis dentro da sociedade, ocupando diversos tipos de atividade no mercado de trabalho, além do doméstico. Dessa forma, seu estilo de vida mudou e, conseqüentemente, mudaram suas necessidades de assistência à saúde. No entanto, o atendimento prestado por parte do médico geralmente não considera essas mudanças, não leva em conta a subjetividade de cada mulher e não percebe que as queixas recebidas - na maioria das vezes expressas por sintomas físicos ou psíquicos decorrentes de problemas econômicos e sociais, desajustes familiares, entre outros - devem ser entendidas de uma maneira mais abrangente, considerando as várias implicações que perpassam essa problemática. Sem saber lidar com tais problemas lançam mão da medicação como único recurso disponível e de fácil acesso.

Analisando os discursos dos médicos prescritores de Diazepam ${ }^{8}$, Oliveira (2000) conclui que esses profissionais
Comprovam que as pessoas de classes baixas e vitimadas por injustiças sociais utilizam o Diazepam como um amortecedor social, já que não há políticas efetivas, e para essas classes sociais é restrito o acesso aos bens sociais, entre os quais se inclui uma assistência de qualidade à saúde. (p. 107)

Tal autora afirma também que os critérios adotados pelos profissionais médicos são frágeis, construídos ao longo de um sistema de saúde que sempre priorizou o lucro, deixando, para segundo plano, o indivíduo em sua totalidade. Segundo ela, "medicar o sofrimento e a dor do dia-a-dia, impregnados de problemas sociais, com tranqüilizantes é uma saída encontrada por um grande contingente de médicos, que se mostram passivos e coniventes com um adoecimento individual e coletivo" (Oliveira, 2000, p. 108).

Em função disso, podemos afirmar que o serviço de saúde não abre espaço para as mulheres serem agentes de mudança de seus próprios processos e desenvolverem sua capacidade auto-reflexiva sobre as reações e sinais do seu corpo e de sua sexualidade. Ou seja, o serviço de saúde não funciona como locus de acolhimento e transformação. Diante dessa realidade, torna-se necessário pensarmos a respeito, para que seja possível encontrar alguns pontos passíveis de mudança.

A seguir apresentaremos nosso trabalho de pesquisa buscando articular os três eixos inicialmente propostos: a fala das mulheres e sua subjetividade, o simbolismo do medicamento e o modelo de atenção à saúde.

\section{A pesquisa com mulheres usuárias de ansiolíticos}

\section{Local, participantes, instrumentos e análise dos dados}

A pesquisa foi realizada junto ao Centro de Saúde Monte Líbano, localizado no bairro das Quintas, em Natal, Rio Grande do Norte. Esse centro pertence ao Distrito Sanitário Oeste, vinculado à Secretaria Municipal de Saúde (SMS) da cidade de Natal. O referido centro de saúde pertence a um bairro bastante populoso, onde há grande demanda no consumo dos serviços de saúde. A estratégia de acesso aos participantes foi realizar um levantamento prévio na farmácia da unidade verificando qual o profissional que mais prescrevia ansiolíticos. O levantamento indicou o clínico geral. Tal dado confirmou o que a literatura aponta, no sentido de ser esse o profissional que mais prescreve ansiolíticos na saúde (Bucher, 1992). A partir disso, definimos os respondentes: mulheres usuárias de ansiolíticos que procuravam atendimento com o clínico geral. Foram realizadas dezessete entrevistas com mulheres que usavam o medicamento há pelo menos três meses, período que já pode ser caracterizado como crítico devido ao aumento das chances de se estabelecer a dependência. $\mathrm{O}$ acesso à mulher usuária foi obtido através da indicação do clínico geral durante a consulta, sendo as entrevistas realizadas após esse encaminhamento para a entrevistadora, numa sala ao lado do consultório médico. O instrumento utilizado foi uma entrevista semi-estruturada. Para 
analisar os dados obtidos através das entrevistas, tomamos como referência a técnica de análise das práticas discursivas, apresentada por Spink (1999), a qual é definida por ela como "linguagem em ação, isto é, as maneiras a partir das quais as pessoas produzem sentidos e se posicionam em relações sociais cotidianas” (p. 45). Tal técnica enfoca as diferentes maneiras com que as pessoas, através do discurso, produzem realidades psicológicas e sociais.

\section{Resultados e discussão}

Os resultados da pesquisa apontaram que a freqüência de uso desse medicamento por parte das mulheres entrevistadas está associada, para a maioria delas, a algum tratamento já iniciado e que precisa do acompanhamento do clínico. Esse fato foi confirmado ao investigarmos o motivo da procura pelo clínico no dia da entrevista. Nove delas alegaram ser hipertensas, necessitando do controle mensal da doença pelo clínico; seis vieram ao serviço apenas pegar a receita do ansiolítico com esse profissional e apenas duas sentiram-se doentes naquele dia. Portanto, a freqüência ao serviço apresentou-se sistemática para a maior parte dessas mulheres, em função do tratamento da hipertensão: onze delas vêm uma vez por mês ao serviço de saúde para o controle da doença; três aparecem com um intervalo de dois a três meses; duas afirmaram que procuram o serviço quando estão doentes e apenas uma afirmou que aparece raramente.

Fica clara a existência de uma relação entre a hipertensão e o uso de ansiolítico, como também uma maior proporção de uso entre as hipertensas, as quais constituem a maioria das entrevistadas. Tal medicamento aparece como um recurso importante utilizado pelo médico no tratamento dessa doença, sendo utilizado com muita freqüência, visando um controle do estado emocional dessas mulheres. Por isso, podemos considerar que esse procedimento resulta numa contribuição direta para um uso crônico, tendo em vista que treze mulheres, portanto, a maioria, toma ansiolíticos todos os dias. O trabalho de Leibeing e Groisman (2001), a respeito de mulheres hipertensas na Favela da Mangueira, Rio de Janeiro, traz a necessidade de discutir um aspecto importante, comum às nossas usuárias locais: o estresse com os problemas familiares ou conjugais contribui para elevar a pressão sangüínea das mulheres, mas há um outro fator que parece atravessar a fala de todas: a vivência da violência. Física ou simbólica, a ausência de remédios contra a violência esbarra na tentação de psiquiatrizá-la. O ansiolítico aparece como um recurso legítimo e capaz de responder satisfatoriamente a esse malestar na medida em que aprisiona a resistência, as linhas de fuga e os “discursos de contra-poder” (Foucault, 1984, p. 76), isto é, o mal-estar e seus determinantes são impedidos de se manifestar.

O ansiolítico utilizado foi, na maior parte dos casos, prescrito, inicialmente, por profissionais de outras instituições: nove mulheres afirmaram que o medicamento não foi receitado pela primeira vez pelo médico do posto em que foi realizada a pesquisa, enquanto que oito delas iniciaram o uso através do clínico desse serviço. Muitas das usuárias procuram esse profissional apenas para renovar a receita, o que mostra a velha prática da continuação de prescrições desses medicamentos com a falta de rigidez nos critérios.

O medicamento mais utilizado pelas mulheres entrevistadas foi o Diazepam, o qual é usado por doze delas, enquanto as outras cinco usam outras marcas de ansiolíticos (Frontal, Lexotam, Lorax, Tranquilizene e Diempax). Tal dado confirma o fato de o Diazepam ser a droga mais conhecida e ainda consumida no grupo de medicamentos ansiolíticos, tendo entre os seus maiores consumidores mulheres e pessoas idosas, que recorrem a prescrições duas vezes mais que os homens, como é apontado por Bucher (1992) e Wortmann et al. (1994), entre outros.

A freqüência de uso indicou que o medicamento é, para a maioria dessas mulheres, algo que faz parte da sua rotina, dos seus hábitos. Treze (das dezessete mulheres) tomam o medicamento todos os dias, enquanto somente quatro delas consomem esporadicamente, quando sentem os sintomas que motivaram o uso. Isso nos aponta para o desconhecimento dessas mulheres a respeito dos efeitos que esses medicamentos podem ter sobre a sua saúde, o que poderia levá-las a algum questionamento sobre esse uso. Provavelmente, acreditam estar fazendo o melhor para si, ou não encontram outra saída para aliviar suas tensões cotidianas. Estão, no dizer de Rosa (1997), “atingidos em seus desejos, limitados no que diz respeito à imaginação e criatividade, não sendo capazes de assumir integralmente a força de suas próprias existências, os indivíduos, seqüestrados em sua intimidade, no limite, não dominam suas idéias, não têm firmeza de vontade...” (p. 257).

A dose prescrita inicialmente pelo médico se manteve para a maioria das mulheres. Treze continuaram tomando a mesma dosagem desde o início do uso, enquanto as outras quatro mulheres dobraram a dose prescrita, sendo que duas delas agiram por conta própria. Em relação a esta última condição, podemos nos reportar, mais uma vez, ao fenômeno da tolerância, devido ao qual ocorre a utilização de doses cada vez maiores para a obtenção dos efeitos que foram obtidos com doses menores. Os seguintes relatos dão uma idéia a respeito dos motivos que levam à concretização do aumento da dose para que o medicamento cumpra a função de alívio perante estados de desespero: (a) “Quando mataram um rapaz perto da minha casa passei muito mal, me vi agoniada e tomei dois” (Mulher de 48 anos); (b) "Eu só aumento quando estou agoniada demais. Tem hora que eu me agonio, corro para o quarto, quebro os óculos, quebro o relógio, o que tiver na mão saio quebrando” (usuária de 58 anos que chega a tomar, por conta própria, quatro comprimidos de $10 \mathrm{mg}$ de uma vez, o que equivale a quatro vezes mais a dose prescrita pelo médico).

Para momentos de forte tensão, o medicamento assume, na vida dessas mulheres, uma importância singular, na medida em que é o responsável por controlar a agonia vivenciada. Elas imaginam que, tomando o medicamento, conseguirão dar conta dos acontecimentos violentos presentes no seu dia-a-dia, ou ainda manterão um comportamento nor- 
mal. O medicamento tem, portanto, o objetivo de agir sobre as suas angústias, seus fantasmas, para que possam se manter “equilibradas”, mesmo em se tratando de uma mordaça química, que as impossibilita de descobrir outras formas de lidar com essas perturbações "nervosas" e seus determinantes individuais e coletivos. Trata-se do esvaziamento do corpo, da paralisação das máquinas desejantes relatados por Paiva (2000), que cristaliza identidades, adestra corpos e dociliza almas.

O tempo de uso do ansiolítico variou de três meses a mais de vinte anos: seis (das dezessete mulheres entrevistadas) utilizam-no há um período de três meses a três anos; quatro delas, de quatro a seis anos; duas usam de doze a quinze anos; e cinco delas há vinte anos ou mais. Independentemente do uso do medicamento ser cotidiano ou somente ocasional, observamos que o mesmo ocupa um lugar imprescindível na vida dessas mulheres, principalmente em se tratando daquelas que o utilizam a um longo tempo.

Oliveira (2000), ao analisar a questão do tempo em sua pesquisa com mulheres usuárias de Diazepam, afirmou que os dados revelaram a maneira como esses casos são tratados no serviço de saúde, em que não há um acompanhamento sistemático das pacientes por parte dos médicos. Com isso, eles perdem de vista essas mulheres, que passam a utilizar tais medicamentos por longos períodos, o que constitui um grave risco para a saúde.

Sougey, Cunha, Barreto e Acioli (1987) esclarecem que limitar o uso do BDZ ao tempo estritamente necessário é a medida mais eficaz na prevenção do abuso ou da dependência desses produtos. Esses autores enfatizam ser fundamental que, desde as primeiras consultas, seja previsto com o paciente o tempo necessário para o tratamento. Há um consenso na literatura especializada de que os BDZ deveriam ser administrados durante um período que varia entre duas a doze semanas e ser retirado gradualmente. No entanto, não parece ser isso o que acontece no âmbito da saúde pública. Os dados expostos revelam um quadro de enorme gravidade, no que se refere à medicalização da mulher, com utilizações crônicas, que podem trazer conseqüências graves para a saúde. De fato, é no mínimo assustador que sete das dezessete mulheres entrevistadas utilizem drogas desse tipo por um período que abrange de doze a mais de vinte anos. Infelizmente, essa é uma realidade presente, de forma crônica, na maioria dos serviços públicos de saúde do nosso país, tal como apontado nas referências anteriormente citadas.

O uso inicial do ansiolítico pelas mulheres entrevistadas ocorreu em sua totalidade a partir da orientação do médico, o que representa um aspecto positivo, pois indica a ausência da auto-medicação. No entanto, tal fato ocorre devido à aquisição do medicamento apenas ser possível com a presença da receita. Por outro lado, o medicamento representa, na relação médico/usuária, o poder que esse profissional exerce, na medida em que é ele “quem sabe o que é bom” para a paciente. Nessa relação, existe geralmente uma submissão cega ao saber e à figura do médico enquanto autoridade que não pode ser colocada em dúvida, principalmente se o profissional é aquele que a acompanha há muito tempo.
A posição da seguinte usuária expressa, de forma transparente, a concepção a respeito desse profissional tão arraigada em nossa cultura:

Se ele mandar tomar veneno, eu acho que eu tomo, tranqüila e calma. Se ele manda: “tome esse remédio aqui”, eu acho que eu tomo e me sinto bem, entendeu? Eu acho que foi igual a uma confiança né, que eu peguei dele assim, passa e eu confiei nele assim, né? Graças a Deus até hoje eu não tenho o que dizer dele, ele é um médico muito bom, passou um remédio muito bom. Pode quem quiser falar, mas para mim, graças a Deus, todo remédio que ele passa é bom. (usuária de 42 anos referindo-se ao clínico do posto, pelo qual é atendida há muito tempo)

Tal discurso retrata, de maneira extremamente clara, a relação de poder estabelecida pelo complexo médico-industrial sobre a mulher usuária, através da imposição do medicamento que, como foi mostrado, tem no médico o seu maior representante. Este, por sua vez, esconde-se por trás do modelo de saúde vigente, que não permite uma postura diferenciada frente aos problemas de saúde, a não ser através do ato de prescrever. Além disso, a figura do médico é vista e tratada como uma autoridade com um saber inquestionável e inabalável a quem se deve respeito e obediência. Por outro lado, o saber da usuária é, por ela própria, desconsiderado, o que faz com que a palavra e o conhecimento de si sejam oferecidos ao médico, que, visto como onipotente, saberá fornecer a solução mágica para o seu problema. Inseridos em uma sociedade de controle, tal como concebida por Deleuze (1992), caracterizada não mais pelo confinamento, mas pelo controle contínuo e comunicação instantânea, e imersos em relações de poder, tais mulheres e médicos estão mergulhados num jogo de forças sempre renovado. Nesse jogo, o prestígio, a informação e o conhecimento são os valores máximos que consolidam autoridade e poder. O médico passa a exercer o poder disciplinar, segundo Foucault (1988), marcado pela invisibilidade e onipresença na busca do controle do tempo, do corpo e da vida das pessoas, criando saberes/verdades. Em outras palavras, "o poder, em seu exercício constante, administra as necessidades dos indivíduos, moraliza suas almas, gere suas intimidades, disseminando, enfim, nas mais variadas relações sociais, o binômio dominação-sujeição” (Rosa, 1997, p. 236).

Ao discutir o caráter educativo existente na relação médico-paciente, Ramos, Melo e Soares (1989) afirmam que "a prática médica exige uma verdadeira conversão do paciente às normas do médico, o qual tem uma função quase apostólica” (p. 148). Ainda segundo esses autores:

Resta uma relação reificada, objetivada, autoritária e inculcadora de um saber que pretende estabelecer e impor a ordem médica. Esta ordem, este saber que se impõe pelo poder do discurso médico, carrega consigo o saber e o poder de uma ordem dominante, a ordem capitalista. (p. 149)

Podemos entender que, à medida que o médico e o paciente são convertidos às normas de atendimento e tratamento do modelo hegemônico, eles são, ao mesmo tempo, convertidos às normas sociais da classe dominante. Por isso, devemos atentar para o caráter ideológico das práticas 
educativas em saúde (ensinamentos dos médicos sobre cuidados com o corpo, com a saúde, com a prevenção e tratamento das doenças). Para Ramos et al. (1989), "tais práticas baseiam-se nas teorias que tomam a educação como instrumento, seja de adaptação à ordem social, seja formando 'boas consciências', bons cidadãos para, assim, aperfeiçoar a sociedade” (p. 151).

Tentamos investigar a respeito da auto-medicação entre as mulheres entrevistadas, perguntando-lhes se já haviam sido aconselhadas por alguém, que não fosse o médico, a usar esse tipo de medicamento, ou se já haviam usado de outra pessoa. Quinze responderam negativamente e apenas duas já pegaram-no emprestado com vizinhos quando dele não dispunham. Percebemos, na maioria, uma obediência à orientação do médico, seguindo as prescrições, como também certo receio de que o uso sem orientação venha a fazer mal, como mostra o seguinte discurso: "Eu não uso medicamento nenhum de outra pessoa porque eu tenho medo... vou usar o medicamento, aí vou e morro” (usuária de 47 anos).

Os ansiolíticos utilizados por dez das mulheres da presente pesquisa são adquiridos gratuitamente nas unidades de saúde mediante apresentação da receita, enquanto que sete delas compram em farmácias. No entanto, essa distribuição apresenta algumas irregularidades, pois há períodos de falta do medicamento ou restrições no que se refere à quantidade a ser distribuída. Tal fato também foi percebido na cidade onde foi realizada a pesquisa de Oliveira (2000), em que a distribuição dos medicamentos da rede pública de saúde acontece também de forma irregular, principalmente quando se trata de Diazepam, pois a demanda é sempre maior do que a oferta, o que leva muitos consumidores a ficarem sem o medicamento, mesmo possuindo a receita.

A maioria das mulheres entrevistadas (onze) não utiliza nenhum outro recurso, fora o medicamento, no enfrentamento dos seus problemas. Quatro delas fazem uso de chás e apenas duas usam suco de maracujá ou remédio à base dessa fruta. O uso desses outros recursos parece ter uma importância secundária, pois ocorre esporadicamente, levando-nos à conclusão de que não há uma crença forte no poder do seu efeito, ao contrário do medicamento. O uso desses artifícios também apareceu como tentativa de deixar o ansiolítico devido à dependência estabelecida. O discurso abaixo expressa um sentimento de preocupação relativo à dependência, em que a usuária parece se sentir aprisionada ao medicamento, desejando se libertar:

Porque eu tenho vontade de me libertar, mas eu tenho vontade de tomar, porque quando não consegue esse medicamento, aí vem tudo de novo, se eles não comprarem. Porque tem vez que meu marido diz assim: "eu não vou comprar, você vai ter que deixar de tomar isso”. Aí volta tudo de novo. (usuária de 44 anos)

\section{Considerações Finais}

Ao analisarmos as questões trazidas nessa pesquisa, consideramos que não podemos perder de vista que uma compreensão mais ampliada do fenômeno do uso de ansiolíticos por mulheres deve estar ancorada em aspectos do seu contexto sociocultural e econômico, o qual determina as suas condições de existência. Por isso, é preciso observar em que medida questões tais como a sexualidade, as relações assimétricas de poder entre o masculino e o feminino, a relação com as instituições de saúde, a divisão sexual do trabalho, a falta de oportunidades concretas de mudança de vida, dentre outros, são condicionantes importantes desse uso. Apesar de não termos investigado todos esses aspectos em profundidade, as falas das mulheres sugerem que são nas relações cotidianas, seja em casa, no trabalho ou na comunidade, que estão situadas as fontes que motivam o uso de ansiolíticos. Ou seja, não podemos desconsiderar os elementos que dizem respeito à subjetividade de cada uma das mulheres e das relações que estabelecem com o contexto, no qual estão inseridas. Corroborando essa afirmação, Bock (2001) expõe uma noção de subjetividade que se constitui na relação com o mundo material e social a partir da perspectiva da psicologia sócio-histórica. Consideramos tal noção importante para a compreensão do nosso estudo, pois se trata de uma concepção de subjetividade produzida por sujeitos concretos que são, ao mesmo tempo, constituídos social e historicamente:

Falar da subjetividade humana é falar da objetividade em que vivem os homens. A compreensão do "mundo interno" exige a compreensão do "mundo externo”, pois são dois aspectos de um mesmo movimento, de um processo no qual o homem atua e constrói/modifica o mundo e este, por sua vez, propicia os elementos para a construção psicológica do homem (Bock, 2001, p. 22).

Portanto, na medida em que a mulher for escutada em sua singularidade, abre-se uma possibilidade para que ela, a partir da relação com o outro, reflita sobre as suas dificuldades, seus desejos, com vistas a atingir novos caminhos, novas perspectivas para a sua vida. No entanto, ficou claro que no modelo de assistência oferecido é dada pouca importância à subjetividade, à individualidade das mulheres, desconsiderando o seu sofrimento e suas angústias.

Podemos entender melhor a inadequação dessa prática ao nos reportarmos à assertiva de Minayo e Souza (1989) a respeito da falta de entendimento e de comunicação, estabelecidos na relação entre o médico do serviço público de saúde e o paciente da classe trabalhadora, no momento da consulta:

Na verdade, no consultório médico, esses grupos sociais transferem para os profissionais de saúde seu grito fundamental: “Nossa dor é a dor de nossa vida”. E do outro lado da cadeira, num diálogo de surdos, o clínico lhes pergunta: “Onde está localizada, em que órgão de seu corpo posso ler essa mensagem?” E muitas vezes, os calmantes, psicotrópicos, os analgésicos são as únicas respostas que ele aprendeu a dar às conhecidas “doenças inespecíficas”. (p. 92)

No contexto desse modelo assistencial, o medicamento ansiolítico pode ser considerado um mecanismo ideológi- 
co, na medida em que oculta os aspectos sociais do processo saúde/doença dessas mulheres, o que torna o seu uso justificado, perpetuado e concebido como natural, além de servir aos interesses econômicos da sociedade capitalista.

Consideramos importante rever nossas posturas profissionais, enquanto pesquisadores e técnicos do campo psicológico, as quais têm ocultado as produções sociais na construção das noções e teorizações sobre o fenômeno psicológico. Devemos ter em vista que o fenômeno do uso de ansiolítico está relacionado a um amplo universo sociocultural e econômico, em que existem várias implicações e determinantes variados. Não podemos deixar de ter uma visão do uso do ansiolítico como algo conectado com as questões sociais amplas, pois corremos o risco de naturalizá-lo e de encontrar justificativas para a manutenção desse estado de coisas.

É importante investir na criação de condições, de espaços, para que as mulheres possam construir novos sentidos para o seu cotidiano. É preciso possibilitar uma expansão do seu campo subjetivo, a fim de que possam perceber o lugar ocupado pelo medicamento em suas vidas. Não se trata de fazer com seu uso seja eliminado, o que seria uma atitude além de impossível, irresponsável, pois mudanças dessa natureza não acontecem de forma abrupta. Devemos lutar para que o ansiolítico seja retirado da posição de “objeto mágico”, concepção que impede essas mulheres de terem uma compreensão e um comprometimento no que se refere à sua saúde e à sua doença. A nosso ver, no momento em que o significado atribuído ao ansiolítico for reconstruído, ou seja, quando ele não for mais visto como "a força” que elas precisam para suportar os seus sofrimentos cotidianos, é possível que elas possam mudar de posição em relação à percepção dos seus sofrimentos. Isso significaria uma tomada de consciência, no sentido de entender e procurar alternativas para os problemas que as fazem adoecer, tornando-se verdadeiros sujeitos de mudanças, de transformação.

\section{Referências}

Almeida, M., Feuerweker, L. C. M., \& Llanos, M. (1999). Educação dos profissionais de saúde na América Latina: teoria e prática de um movimento em mudança. Tomo 1. São Paulo: Hucitec.

Ayres, J. R. C. M. (2001). Sujeito, intersubjetividade e práticas de saúde. Ciência e Saúde Coletiva, 6(1), 63-72.

Barros, M. B (1983). Saúde e classe social: um estudo sobre morbidade e consumo de medicamentos. Tese de doutorado não-publicada, Universidade Estadual de São Paulo, Ribeirão Preto.

Bucher, R. (1992). Drogas e drogadição no Brasil. Porto Alegre: Artes Médicas.

Bodstein, R. C. A. (1993). Serviços sociais de saúde: construção de atores e políticos. Rio de Janeiro: Relume-Dumará.

Barros, J. A. C. (1995). Propaganda de medicamentos, atentado à saúde? São Paulo: Hucitec.

Bock, A. M. B. (2001). A psicologia sócio-histórica: Uma perspectiva crítica em psicologia. In A. M. B. Bock., M. G. M. Gonçalves, \& O. Furtado, (Orgs.), Psicologia sócio-histórica: uma perspectiva crítica em psicologia (pp. 1535). São Paulo: Cortez.

Campos, G. W. S. (1992). Reforma da reforma: repensando a saúde. São Paulo: Hucitec.
Capra, F. (1982). O ponto de mutação. São Paulo: Cultrix.

Carvalho, L. F. (2001). Dependência química em mulheres: um estudo sobre o consumo de medicamentos ansiolíticos no serviço público de saúde de Natal/RN. Dissertação de Mestrado não-publicada, Universidade Federal do Rio Grande do Norte, Natal.

Deleuze, G. (1992). Conversações. Rio de Janeiro: Editora 34.

Dimenstein, M. D. B. (1998). O psicólogo no contexto do sistema único de saúde (SUS): perfil profissional e perspectivas de atuação nas unidades básicas de saúde (UNB). Tese de doutorado não-publicada, Universidade Federal do Rio de Janeiro, Rio de Janeiro.

Fonseca, R. M. G. S. (1999). Mulher, direito e saúde: repensando o nexo coesivo. Saúde e Sociedade, 8(2), 3-32.

Foucault, M. (1984). Microfísica do poder. Rio de Janeiro: Graal.

Foucault, M. (1988). Vigiar e punir. Petrópolis: Vozes.

Karniol, I. G., Botega, N. J., Maciel, R. R., Moreira, M. E. A., Capitani, E. M., Madureira, P. R., Oliveira Junior, J. F., Portella, V., \& Vieira, R. J. (1986). Uso e abuso de benzodiazepínicos no Brasil. Revista ABP-APAL, 8(1), 3035.

Lefèvre, F. (1983). A função simbólica dos medicamentos. Revista de Saúde Pública, 17, 500-503.

Leibing, A., \& Groisman, D. (2001). Tão alto quanto o morro - identidades localizadas de mulheres hipertensas na Favela da Mangueira. In B. T. Ribeiro, C. C. Lima, \& M. T. L. Dantas (Orgs.), Narrativa, identidade e clínica (pp. 258-276). Rio de Janeiro: Edições IPUB/CUCA.

Melman, J. (2001). Família e doença mental: repensando a relação entre profissionais de saúde e familiares. São Paulo: Escrituras Editora.

Minayo, M. C. S., \& Souza, H. O. (1989). Na dor do corpo, o grito da vida. In N. R. Costa, C. L. Ramos, M. C. S. Minayo, \& E. N. Stotz (Orgs.), Demandas populares, políticas públicas. Coleção saúde e realidade brasileira (pp.75-101), Volume II. Petrópolis: Vozes.

Oliveira, E. N. (2000). Saúde mental e mulheres: sobrevivência, sofrimento e dependência química. Sobral: Edições UVA.

Paiva, A. C. S. (2000). Sujeito e laço social: a produção de subjetividade na arqueologia de Michel Foucault. Rio de Janeiro: Relume-Dumará.

Ramos, C. L., Melo, J. A. C., \& Soares, J. C. R. S. (1989). Quem educa quem? Repensando a relação médico-paciente. In N. R. Costa, C. L. Ramos, M. C. S. Minayo, \& E. N. Stotz, (Orgs.), Demandas populares, políticas públicas. Coleção saúde e realidade brasileira (pp. 145-163), Volume II. Petrópolis: Vozes.

Rosa, M. R. (1997). Subjetividade produzida: poder e disciplina em uma problematização foucaultiana. In D. Baptista, M. Soria, M. L. Silveira, M. R. Silva, M. O. T. Storni, \& V. M. Manfroi (Orgs.), Cidadania e subjetividade: novos contornos e múltiplos sujeitos (pp.229-264). São Paulo: Imaginário.

Rozemberg, B. (1994). O consumo de calmantes e o “problema de nervos” entre lavradores. Revista de Saúde Pública, 28(4), 300-308.

Sougey, E. B., Barreto, J. A. V., \& Acioli, M. D. (1987). Sugestões preventivas da dependência na prescrição de benzodiazepínicos. Jornal Brasileiro de Psiquiatria, 36(6), 325-328.

Soares, C. N., Soares, M. B. M., Asbahr, F. R., \& Bernik, M. A. (1991). Perfil de uso de benzodiazepínicos em pacientes psiquiátricos e não-psiquiátricos. Jornal Brasileiro de Psiquiatria, 40(4), 191-198.

Spink, M. J. P. (1999). Práticas discursivas e produção de sentidos no cotidiano: aproximações teóricas e metodológicas. São Paulo: Cortez.

Seild, E. M. F. (1999). Prevenção ao uso indevido de drogas - diga sim à vida. Brasília: Secretaria Nacional Antidrogas, Universidade de Brasília.

Wortmann, A. C., Grüdtner, M. C., Fialho, A. F., Jardim Neto, J. C., Schaefer, L. G., Sehn, F., Pechansky, F., \& Soibelman, M. (1994). Consumo de benzodiazepínicos em Porto Alegre. Revista da Associação Médica Brasileira, 40(4), 265-270. 
1 Artigo elaborado a partir da dissertação de mestrado apresentada pela primeira autora (Carvalho, 2001) ao Programa de Pós-Graduação em Psicologia da UFRN, e orientada pela segunda. Agradecemos apoio financeiro da CAPES na forma de bolsa de estudos à primeira autora.

2 A Organização Mundial da Saúde (OMS) define a dependência de drogas, em substituição ao termo vício, "como um estado de adaptação mental ou física à droga consumida regularmente, ou seja, quando uma pessoa não consegue mais alcançar seu bem-estar ou executar tarefas cotidianas sem o auxílio de alguma substância psicoativa. Essa dependência pode ser física, psíquica, ou ambas” (Seild, 1999).

3 Classe de medicamentos ansiolíticos mais vendida atualmente, segundo a literatura especializada.

4 Esse fenômeno se caracteriza pela utilização de doses cada vez maiores do medicamento para obtenção dos efeitos anteriormente obtidos com doses menores.

5 Dimenstein (1998), tratando especificamente dos psicólogos na saúde pública, aponta para o fato de que há no serviço público "uma priorização do modelo assistencial individual de forma que, no cálculo rendimento-hora (produtividade/incentivo SUS), não são considerados atendimentos em grupo, nem aqueles ligados à assistência indireta como as visitas domiciliares, aos equipamentos sociais das comunidades” (p. 88).

6 Promoção refere-se ao conjunto amplo de ações não específicas que visam aumentar o nível de consciência sanitária e de cidadania dos indivíduos e das populações, bem como contribuir para a melhoria das condições de vida e saúde; prevenção diz respeito ao conjunto de medidas específicas que objetivam evitar doenças ou agravos à saúde (estão incluídas aqui as medidas de profilaxia ou proteção específica); ações terapêuticas são aquelas especializadas que visam ao restabelecimento total ou parcial da saúde dos indivíduos. É a assistência clínica propriamente dita (Bodstein, 1993, p. 35).

7 Reabilitação diz respeito ao conjunto de ações que visam à recuperação das faculdades físicas, psíquicas e sociais, lesadas após processo de adoecimento (fisioterapia, por exemplo) (Bodstein, 1993).

8 Marca mais vendida de ansiolítico, segundo Bucher (1992) e Wortmann et al, (1994), entre outros.

Lúcia de Fátima Carvalho, mestre em Psicologia pelo Programa de Pós-Graduação em Psicologia da Universidade Federal do Rio Grande do Norte, é psicóloga da Secretaria Municipal de Saúde de Natal. Endereço para correspondência: Rua Monte Sinai, 1872, Cidade Jardim, Natal, RN; CEP 59.078-360. E-mail: lucifatima@uol.com.br

Magda Dimenstein, doutora em Saúde Mental pela Universidade Federal do Rio de Janeiro, é professora no departamento de Psicologia e Programa de Pós-Graduação em Psicologia da Universidade Federal do Rio Grande do Norte. Endereço para correspondência: Av. Praia de Genipabu, 2100, apto. 1402/N, Ponta Negra, Natal, RN; CEP 59.094-010. E-mail: magdad@uol.com.br 